\title{
Selenite-induced autophagy antagonizes apoptosis in colorectal cancer cells in vitro and in vivo
}

\author{
YANG YANG $^{1}, \mathrm{HUI} \mathrm{LUO}^{2}, \mathrm{KAIYUAN} \mathrm{HUI}^{1}, \mathrm{YALI} \mathrm{CI}^{1}, \mathrm{KEJIAN} \mathrm{SHI}^{1}, \mathrm{GE} \mathrm{CHEN}^{3}, \mathrm{LEI} \mathrm{SHI}^{1}$ and $\mathrm{CAIMIN} \mathrm{XU}^{1}$ \\ ${ }^{1}$ State Key Laboratory of Medical Molecular Biology, Department of Biochemistry and Molecular Biology, \\ Institute of Basic Medical Sciences, Chinese Academy of Medical Sciences (CAMS), School of Basic Medicine, \\ Peking Union Medical College (PUMC), Beijing 100005; ${ }^{2}$ Shenzhen University Health Science Center, \\ Shenzhen 518060; ${ }^{3}$ Department of General Surgery, PUMC Hospital, CAMS, Beijing 100730, P.R. China
}

Received September 29, 2015; Accepted November 5, 2015

DOI: $10.3892 /$ or.2015.4484

\begin{abstract}
In the present study, we aimed to investigate the relationship between autophagy and apoptosis in selenite-treated colorectal cancer (CRC) cells. The effects of selenite on HCT116 and SW480 cell apoptosis were investigated with an Annexin V/propidium iodide (PI) double staining kit by flow cytometry. The punctate of LC3 protein following treatment with selenite was observed by a laser scanning confocal microscope and by transmission electron microscopy. Using western blot assays, we detected the apoptotic and autophagic markers in both CRC cells and mouse xenograft tumor models. We found that sodium selenite induced autophagy in the two CRC cell lines. Consistent with the in vitro results, we observed that the expression of autophagy marker LC3 was increased. Finally, we discovered that modulation of reactive oxygen species by MnTMPyP inhibited autophagy, while $\mathrm{H}_{2} \mathrm{O}_{2}$ activated autophagy. These results help to elucidate the anticancer effect of selenium, providing further evidence to exploit novel anticancer drugs targeting selenium.
\end{abstract}

\section{Introduction}

Numerous studies have demonstrated that selenium is an essential trace element, pivotal for human health $(1,2)$. Serum selenium levels are correlated with the incidence of many diseases, of which cancer attracts the utmost attention (3-5). Numerous preclinical and epidemiological studies have demonstrated the chemopreventive efficacy of selenium

Correspondence to: Professor Lei Shi or Professor Caimin Xu, State Key Laboratory of Medical Molecular Biology, Department of Biochemistry and Molecular Biology, Institute of Basic Medical Sciences, Chinese Academy of Medical Sciences (CAMS), School of Basic Medicine, Peking Union Medical College (PUMC), 5 Dong Dan San Tiao, Beijing 100005, P.R. China

E-mail: shilei@ibms.pumc.edu.cn

E-mail: cmxu@ibms.pumc.edu.cn

Key words: selenite, apoptosis, autophagy, colorectal cancer cells, reactive oxygen species against cancers $(6,7)$. Sodium selenite, an inorganic form of selenium, has been shown to induce cancer cell death via various mechanisms $(8,9)$. Numerous studies including ours, have shown that sodium selenite induces the apoptosis of malignant cancer cells such as leukemia, colorectal, lung and prostate cancer $(10,11)$, yet the detailed mechanisms of how selenite induces cell death are far from clear. Colorectal cancer (CRC) is the second leading cause of cancer-related patient death in the US. Thus, there is an urgent need for novel drugs for CRC (12).

Autophagy is an eukaryotic conserved degradative system. When cells are confronted with stress, they form double-membrane autophagosomes to constrain superfluous organelles or long-lived proteins. The crosstalk between autophagy and apoptosis is complicated $(13,14)$. Various studies show that autophagy may cooperate with apoptosis to induce cell death (15-17). We aimed to investigate the relationship between autophagy and apoptosis in selenite-treated CRC cells.

We previously showed that supranutritional sodium induced apoptosis in leukemia and CRC cells (18-20). In the present study, we conducted a series of experiments to unveil the role of autophagy and apoptosis in selenite-treated CRC cells. We validated that sodium selenite induced protective autophagy in CRC cells. Inhibition of autophagy enhanced the apoptosis of the CRC cells, while inhibition of apoptosis resulted in decreased autophagy. These results showed that sodium selenite induced both autophagy and apoptosis in the CRC cells. However, the detailed mechanism underlying the crosstalk between selenite-induced autophagy and apoptosis in CRC cells warrants further study.

\section{Materials and methods}

Cells and antibodies. HCT116 and SW480 CRC cells were maintained in Dulbecco's modified Eagle's medium (DMEM) (Invitrogen, Paisley, Scotland, UK) supplemented with $10 \%$ fetal bovine serum (FBS) (HyClone, Logan, UT, USA), and antibiotics (100 U/ml penicillin and $100 \mu \mathrm{g} / \mathrm{ml}$ streptomycin) in a humidified $5 \% \mathrm{CO}_{2}$ atmosphere at $37^{\circ} \mathrm{C}$. Sodium selenite was purchased from Sigma-Aldrich (St. Louis, MO, USA). Antibodies against cleaved caspase-9, cleaved PARP, LC3 or Beclin-1 were purchased from Cell Signaling Technology 
(Danvers, MA, USA). Antibodies to $\beta$-actin were purchased from Sigma-Aldrich. The p62 antibody was purchased from Abcam (Cambridge, MA, USA).

Protein isolation and immunoblot analysis. Cells were lysed in RIPA buffer (20 mM Tris pH 7.5, $150 \mathrm{mM} \mathrm{NaCl}, 1 \mathrm{mM}$ EDTA, 1 mM EGTA, $1 \%$ Triton X-100, 2.5 mM sodium pyrophosphate, $1 \mathrm{mM} \beta$-glycerolphosphate, $1 \mathrm{mM} \mathrm{Na}_{3} \mathrm{VO}_{4}, 1 \mu \mathrm{g} /$ $\mathrm{ml}$ leupeptin and $1 \mathrm{mM}$ PMSF). The total cell lysates were sonicated and collected by centrifugation prior to concentration determination using the Bradford method. The proteins were resolved on 8-15\% SDS-PAGE, and then electro-transferred to nitrocellulose membranes. Subsequently, the blots were incubated with the indicated primary antibodies and the corresponding HRP-conjugated secondary antibodies. The immunoreactive bands were visualized by chemiluminescent reagents from Thermal Scientific.

Immunofluorescence. Cells were grown on glass slides for $24 \mathrm{~h}$ before treatment with $10 \mu \mathrm{M}$ selenite for $24 \mathrm{~h}$. The cells were incubated with LC3 primary antibodies overnight at $4^{\circ} \mathrm{C}$, and were then incubated with FITC fluorescence-labeled secondary antibodies for $1 \mathrm{~h}$ at room temperature, followed by staining with DAPI solution to visualize the cell nuclei. The punctate of LC3 protein before and after treatment with selenite in the CRC cells was detected by an Olympus laser scanning confocal FV1000 microscope (Olympus, Tokyo, Japan) and analyzed by Olympus FluoView software.

Plasmid transfection. GFP-LC3 plasmids were transfected into HCT116 and SW480 CRC cells using Lipofectamine 2000 according to the manufacturer's instructions. After another $24 \mathrm{~h}$, the cells were treated with selenite or phosphate-buffered saline (PBS) as a solution control. The transfection efficiency was confirmed by western blotting.

Detection of apoptosis by Annexin V/propidium iodide (PI) double staining. The apoptotic rates of cells were determined using an Annexin V/PI double staining kit (Merck, Germany) according to the manufacturer's instructions. Then the cells were subjected to analysis by a C6 Accuri flow cytometer.

Transmission electron microscopy (TEM). TEM was used to observe autophagy and ultrastructural changes in the HCT116 and SW480 cells $24 \mathrm{~h}$ after selenite treatment. Fixed cells were post-fixed in $2 \% \mathrm{OsO}_{4}$, dehydrated in graded alcohol and flat-embedded in Epon 812 (Electron Microscopy Sciences, Fort Washington, PA, USA). Ultra-thin sections $(100 \mathrm{~nm})$ were prepared, stained with uranyl acetate and lead citrate, and examined under an electron microscope (H-600; Hitachi, Japan).

Ethics statement. The present study was approved by the Ethics Committee of the Institute of Basic Medical Science. Principles of laboratory animal care were followed and complied with standards equivalent to the guidelines for the welfare of animals in experimental neoplasia.

Mouse xenograft tumor models. BALB/c nude mice (4 weeks old) were purchased from the Institute of Laboratory Animal sciences. Twenty-eight nu/nu mice were randomly assigned to four groups and subcutaneously injected with HCT116 or SW480 CRC cells which were suspended in serum-free DMEM at a concentration of $2 \times 10^{7}$ cells $/ \mathrm{ml}$ in the left shoulder of the nude mice. After the tumors were palpable, half of the mice were injected i.p. with sodium selenite $(2 \mathrm{mg} / \mathrm{kg} / \mathrm{day})$. The control group was injected with $0.9 \%$ sodium chloride, at a volume of $\sim 200 \mu 1 / 20 \mathrm{~g} / \mathrm{day}$. At the end of the experiment, the mice were sacrificed by cervical dislocation, and the tumors and livers were rapidly removed and weighed.

Immunohistochemical staining. Tumor tissues from the control and selenite-treated groups were sectioned and deparaffinized in xylene and dehydrated with graded ethanols in accordance with the routine method. The slides were incubated with primary antibodies against cleaved caspase-9, Beclin-1, p62 or LC3 overnight at $4^{\circ} \mathrm{C}$. After being washed in PBS, the slides were incubated with HRP-conjugated secondary antibody at room temperature for $2 \mathrm{~h}$ treated with diaminobenzidine working solution, and then counterstained with Mayer's hematoxylin for $1 \mathrm{~min}$. Finally, the slides were dehydrated with increasing concentrations of ethanol and clarified with xylene.

Statistical analysis. All of the above experiments were repeated at least three times. The results are expressed as the mean $\pm \mathrm{SD}(\mathrm{n} \geq 3)$. In addition, Student's t-test was applied to assess the statistically significant difference $(\mathrm{P}<0.05)$.

\section{Results}

Selenite treatment induces autophagy in CRC cells. We previously showed that supranutrional selenite treatment induced apoptosis in HCT116 and SW480 CRC cells (21). As shown in Fig. 1A, the expression of the autophagy markers and Beclin-1, was increased. p62 is a specific substrate of autophagy, which was decreased in response to selenite treatment. We detected the conversion of microtubule-associated protein light chain 3 (LC3) (from LC3-I to LC3-II) in response to selenite treatment. Increased punctate of GFP-LC3 was noted in the cells treated with selenite (Fig. 1B). Consistently, from the electron microscopy results (Fig. 1C), we observed more autophagosomes in the selenite-treated CRC cells. All the results collectively showed that sodium selenite treatment increased autophagy in the HCT116 and SW480 CRC cells.

Autophagy acts as a pro-survival mechanism in the selenitetreated CRC cells. 3-Methyladenine, an inhibitor of autophagy initiation (22), was used to inhibit selenite-induced autophagy. Bafilomycin A1 was used to inhibit the degradation of autophagosomes by lysosomes (23). Using western blotting, we showed that the conversion of LC3 was reduced in the 3-MA-treated samples, and in contrast, however, LC3-II was accumulated in the bafilomycin A1-treated cells. From the western blot results, cleaved PARP and cleaved caspase-9 were greatly increased when autophagy was inhibited compared with selenite treatment alone (Fig. 2A). Additionally, from the Annexin V/PI double staining assay (Fig. 2B), we also concluded that when autophagy was inhibited, the apoptotic rate increased. Rapamycin is widely used to activate autophagy through its inhibitory effect on mTOR. From the western blot 
A

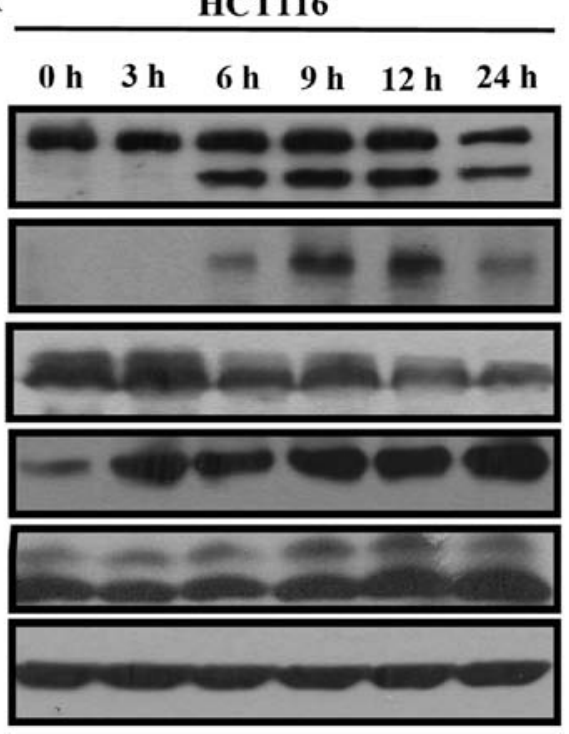

SW480

$\begin{array}{llllllll}0 \mathrm{~h} & 3 \mathrm{~h} & 6 \mathrm{~h} & 9 \mathrm{~h} & 12 \mathrm{~h} & \mathbf{2 4} \mathrm{h} & \text { Selenite }(10 \mu \mathrm{M})\end{array}$

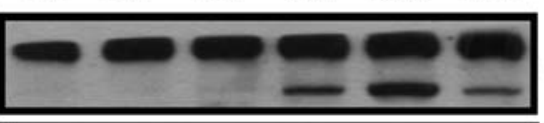

cleaved PARP

cleaved caspase-9

p62

Beclin-1

LC3

$\beta$-actin
B

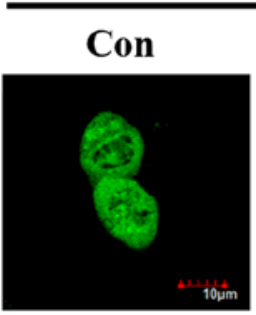

HCT116

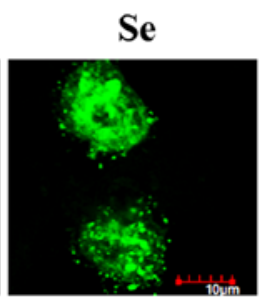

HCT116

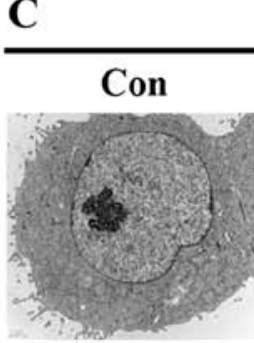

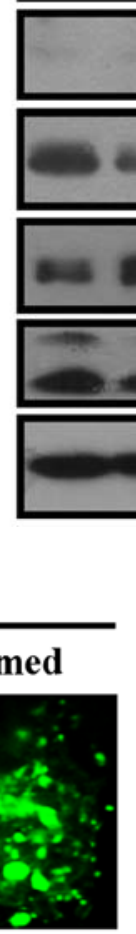
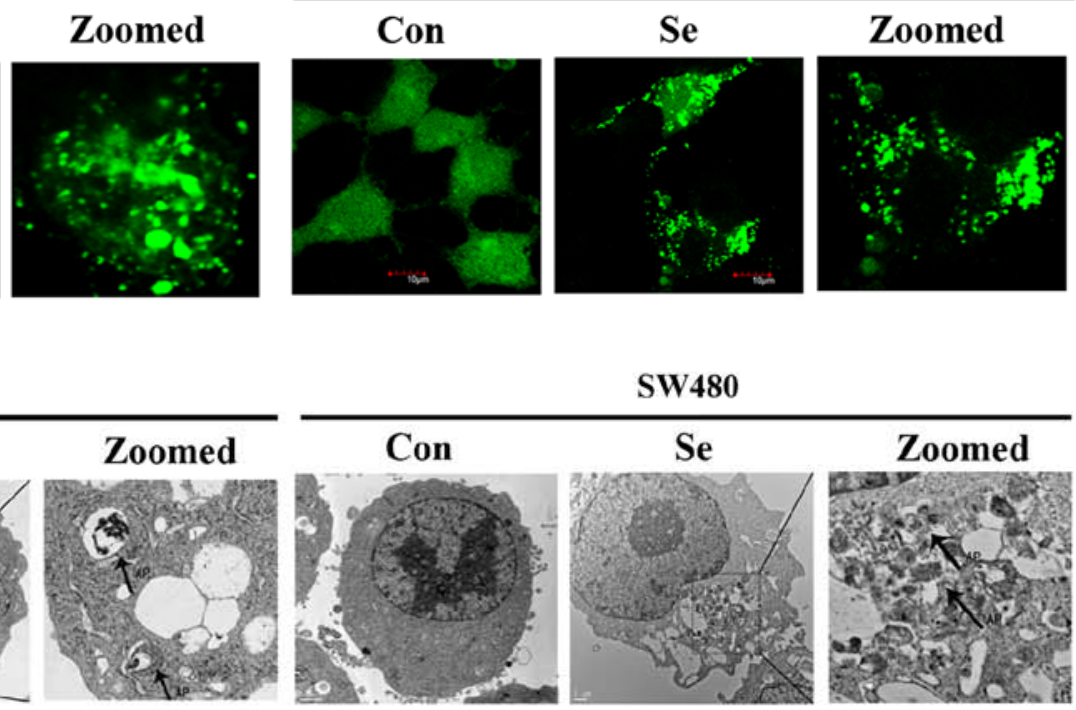

SW480
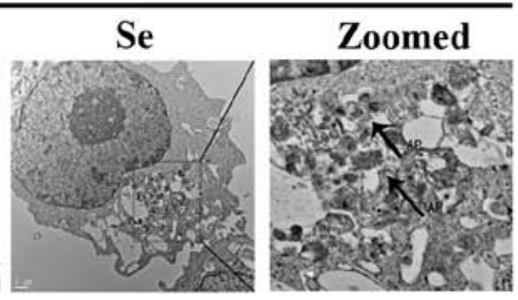

Figure 1. Autophagy is activated in CRC cells by selenite. (A) Western blot analyses of CRC cells treated with sodium selenite for the indicated time periods. Antibodies against cleaved PARP, caspase-9, Beclin-1, p62 and LC3 were probed in the selenite-treated samples. $\beta$-actin was used as a loading control. (B) Confocal results of the distribution of GFP-LC3 in the control and selenite-treated cells. The green signal indicates the location of GFP-LC3 in the cells. Scale bar, $10 \mu \mathrm{m}$. (C) Representative images from electron microscopy experiments. The double membrane autophagosomes are circled and zoomed.

results, we discovered that $\mathrm{LC} 3$ conversion was increased in the rapamycin-treated cells compared with the control or selenite treatment group. By detecting cleaved PARP and caspase-9, we found that the levels of cleaved caspase-9 and PARP were decreased when autophagy was activated (Fig. 2C). In accordance with the western blot results using Annexin V/PI double staining assays, we found that the apoptotic rate was decreased from 30.1 to $15.2 \%$ and 31.1 to $10.3 \%$ in the HCT116 and SW480 cells, respectively (Fig. 2D). When the cells were treated with pan-caspase inhibitor, Z-VAD-fmk, the punctate of LC3 disappeared compared with the control (Fig. 2E). This demonstrated that selenite-induced autophagy was elicited by selenite when apoptosis was induced in CRC cells. These results indicate that autophagy may facilitate the survival of cells by antagonizing the proapoptotic effect of selenite.
Sodium selenite treatment inhibits tumor growth and induces apoptosis and autophagy in HCT116 and SW480 colorectal xenograft models. To further investigate the effect of sodium selenite on the growth of tumors in xenograft models, we subcutaneously inoculated HCT116 and SW480 cells in nude mice and developed tumors to a palpable size. Sodium selenite diet was given daily. After 21 days, the tumors were extracted and photographed. The results are shown in Fig. 3A and B; $2 \mathrm{mg} / \mathrm{kg} /$ day selenite treatment inhibited both HCT116 and SW480 tumor volume. The tumor weight was analyzed and the results are show in Fig. 3A and B (upper panel). Tumor weight in the $2 \mathrm{mg} / \mathrm{kg} /$ day selenite treatment group was significantly decreased compared with the control. Moreover, sodium selenite treatment had no obvious effect on the body weight of the mice (Fig. 3C and D). By H\&E staining of the tumor 

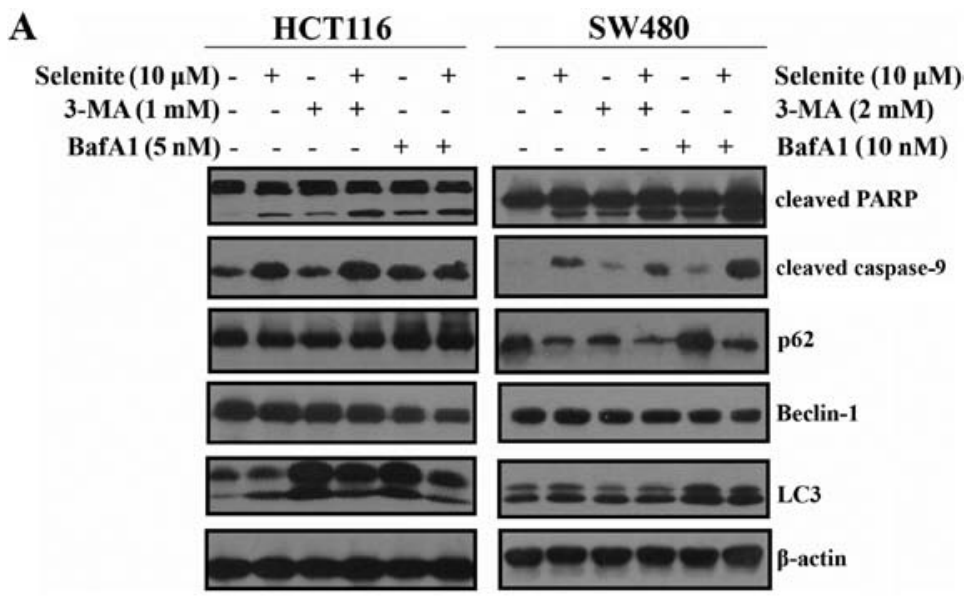

B

HCT116
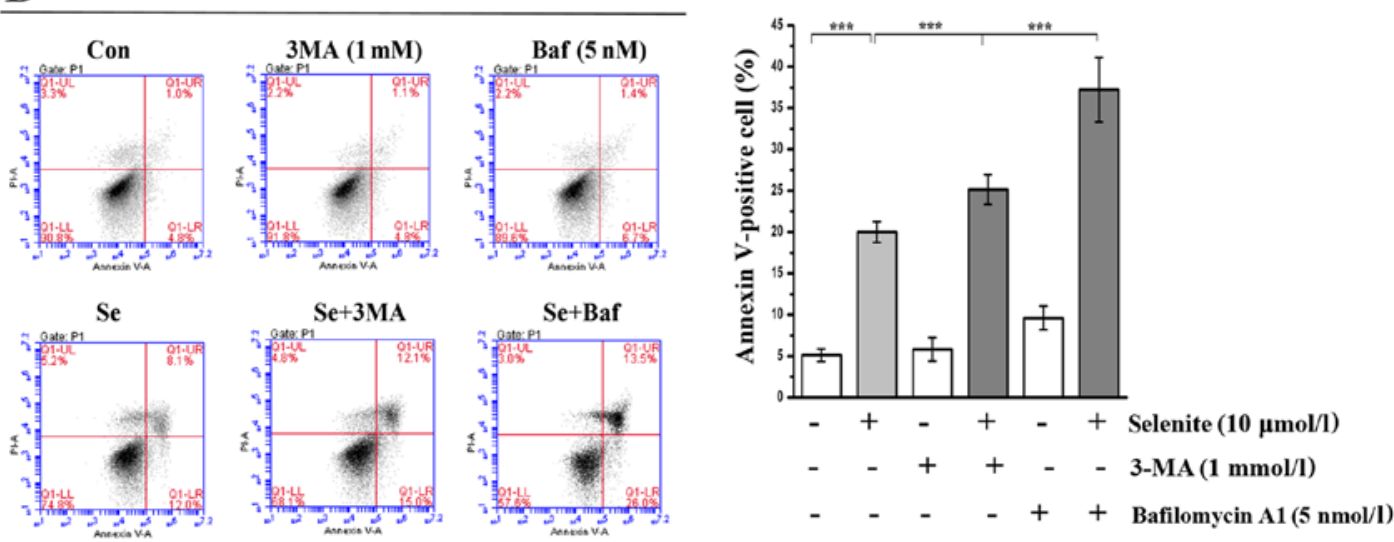

SW480
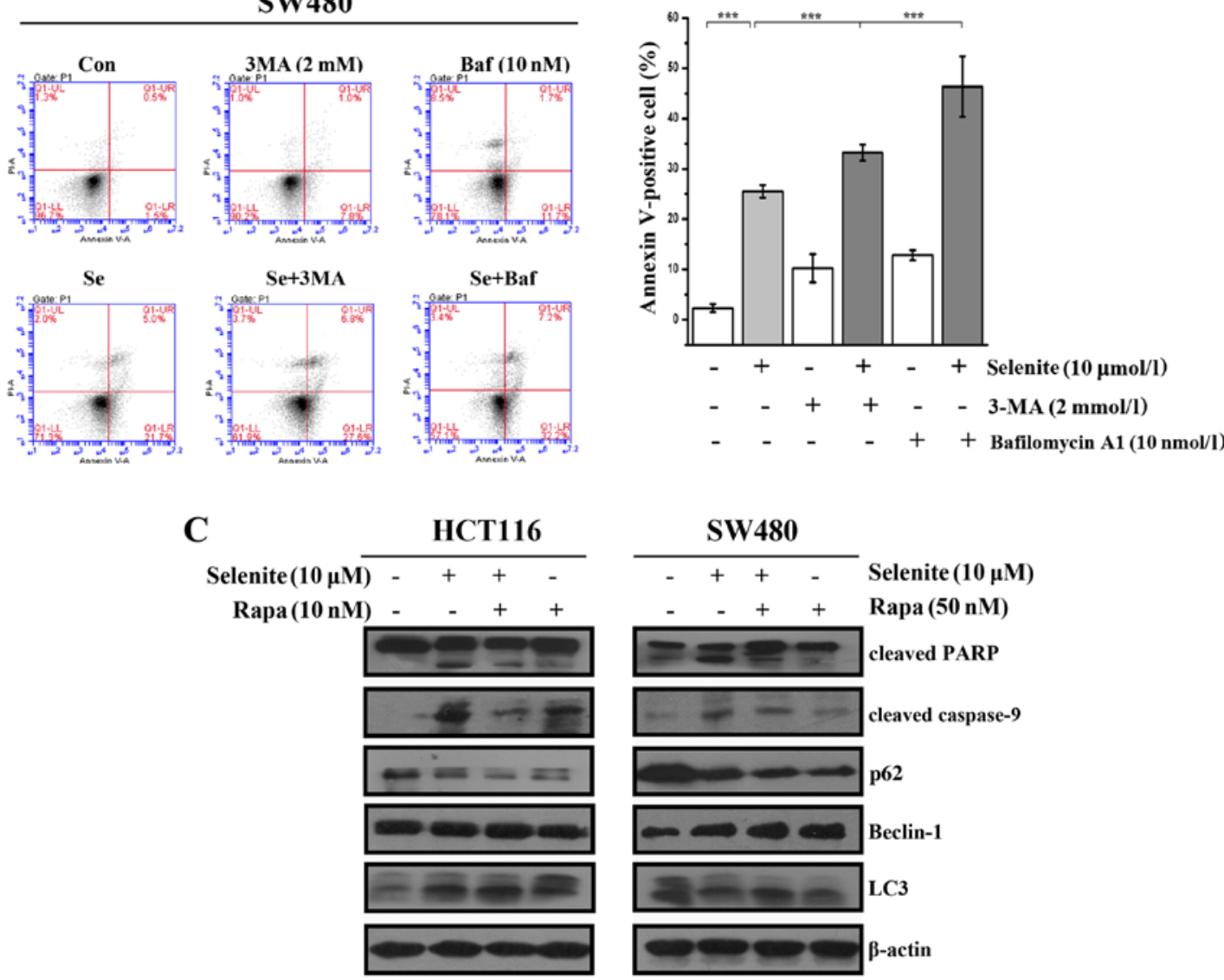

Figure 2. Inhibition of autophagy enhances the apoptosis of CRC cells. (A) HCT116 and SW480 CRC cells were treated with sodium selenite and 3-MA and bafilomycin A1. (B) Flow cytometry results of the samples from the selenite-treated HCT116 and SW480 CRC cells at $24 \mathrm{~h}$ with or without 3-MA and bafilomycin A1. (C) Cells were treated with sodium selenite combined with rapamycin or without. 
D
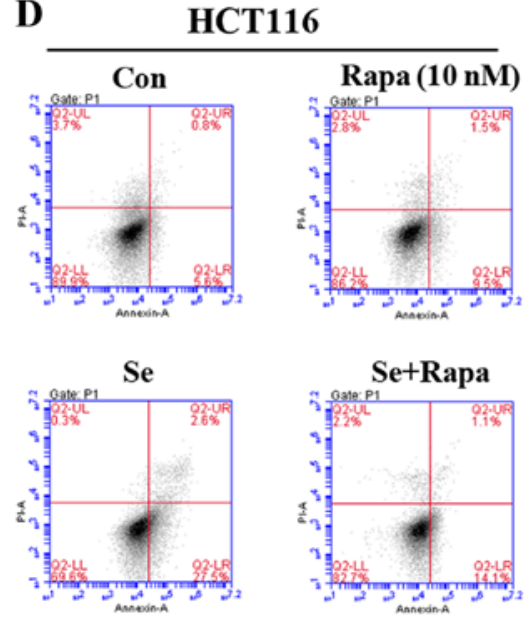

SW480
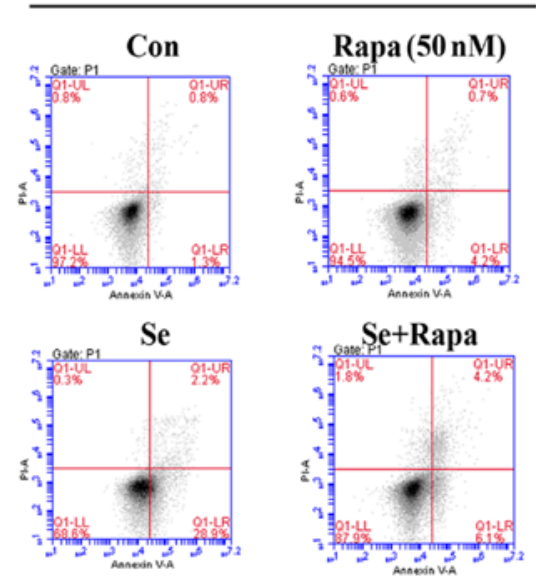

E
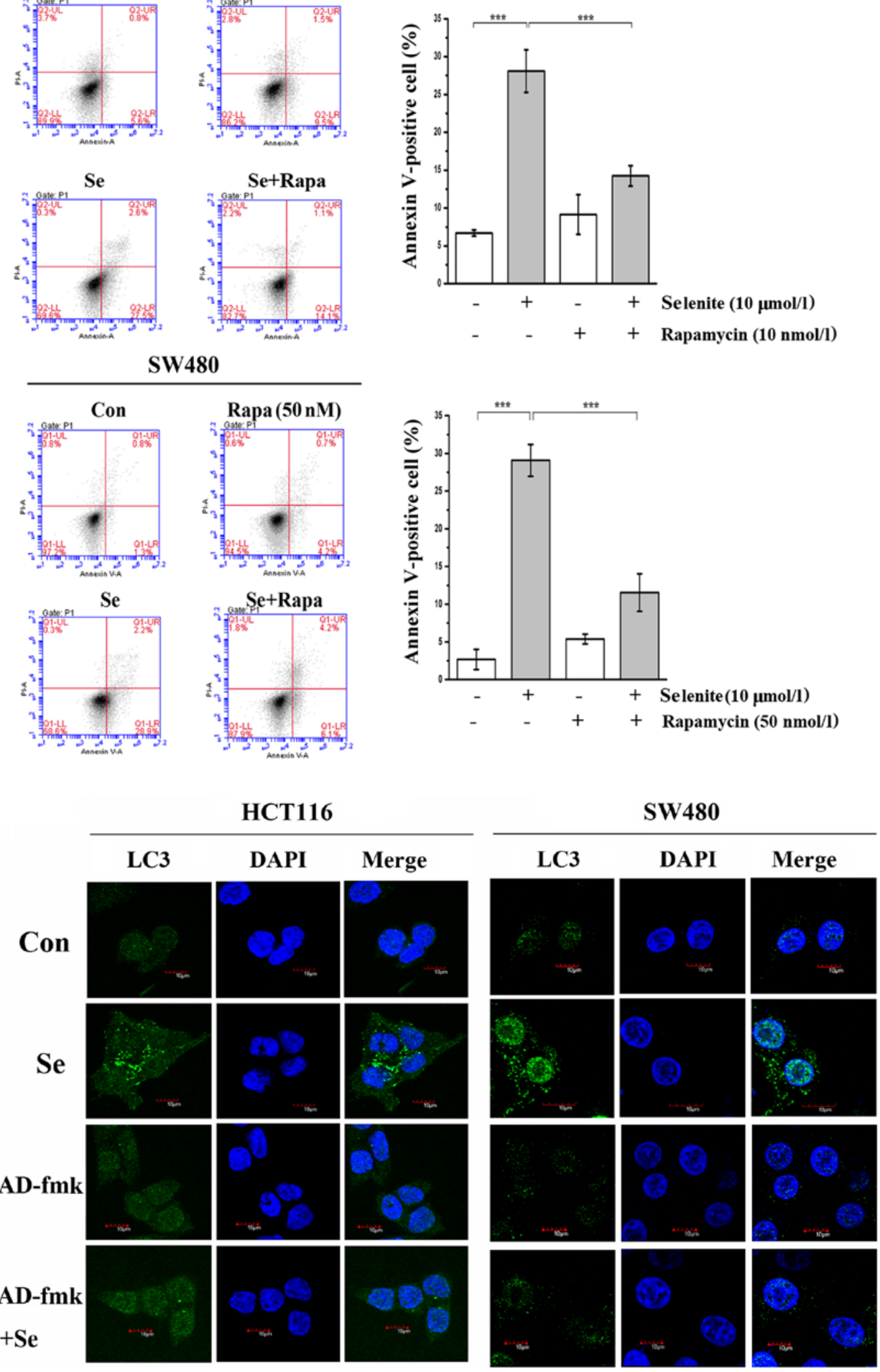

SW480

Figure 2. Continued. (D) FACS results of the samples from C. (E) Representative images of HCT116 and SW480 cells treated with selenite or selenite in combination with Z-VAD-fmk. Green signal indicates LC3, and nuclei were stained with DAPI solution. Scale bar, $10 \mu \mathrm{m}$.

and liver, compared with the control group, the selenite-treated group showed more pathological changes including some 
A
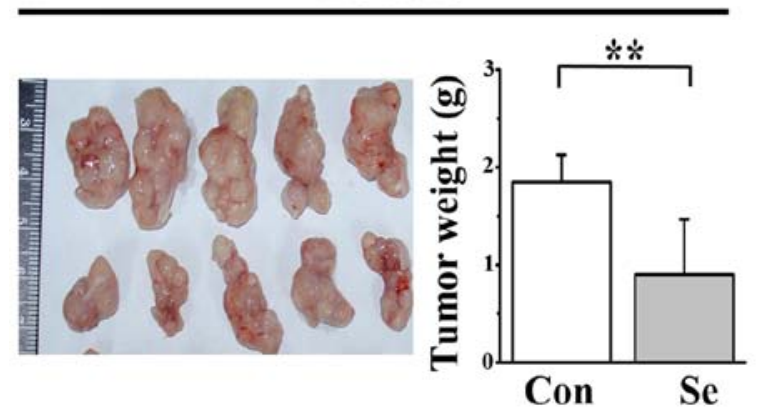

B
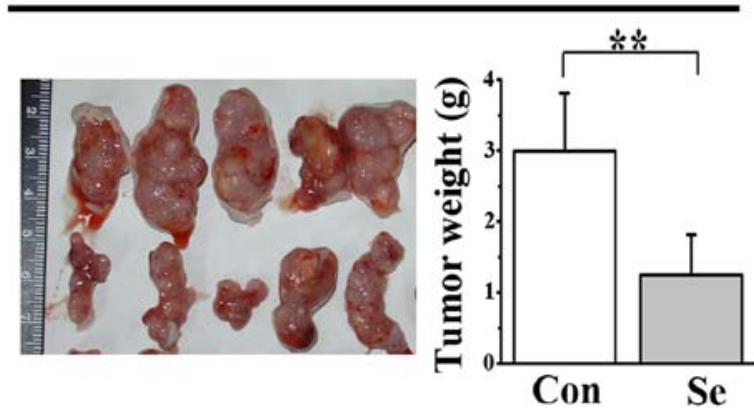

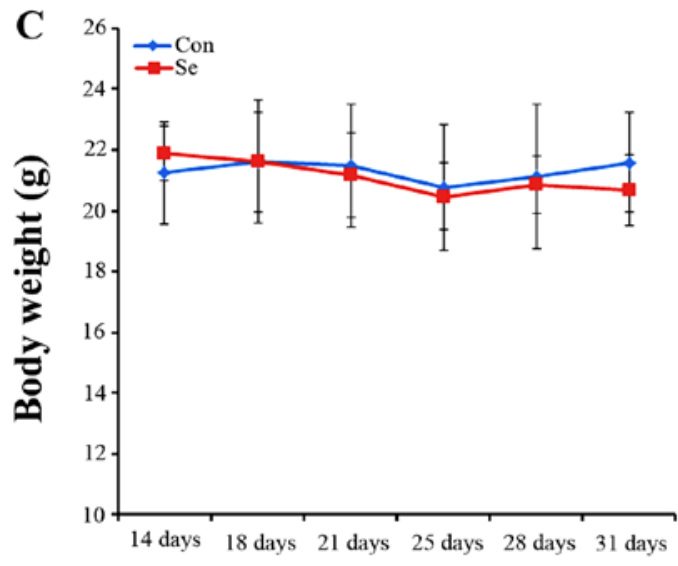

Days after implantation (HCT116)

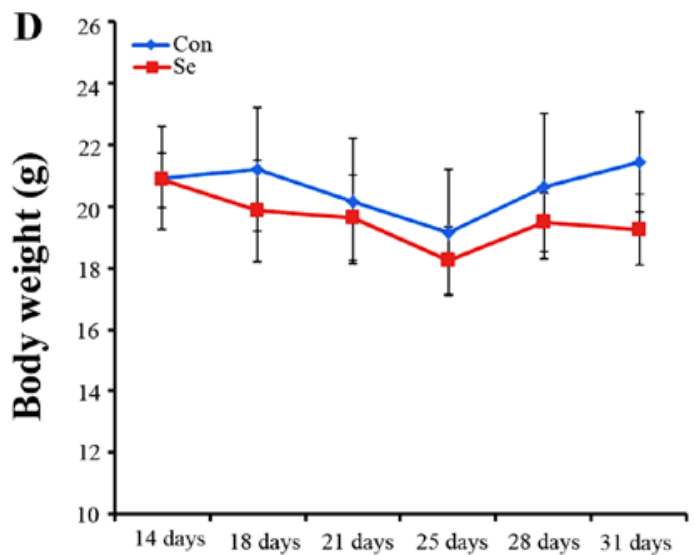

Days after implantation (SW480)
$\mathbf{E}$

HCT116

Con Se

Tumor (H\&E)

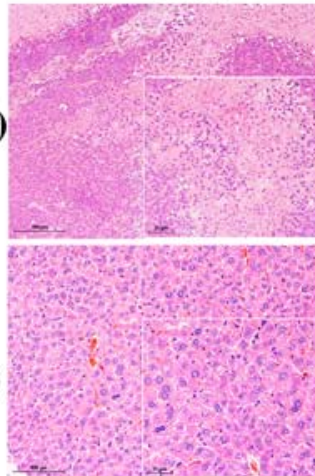

Se

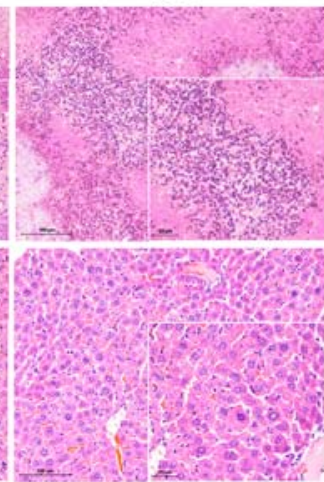

SW480

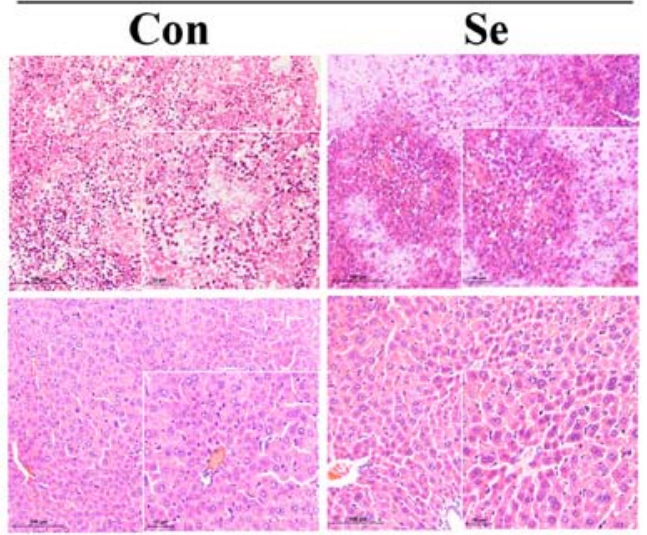

Figure 3. Sodium selenite treatment inhibits tumor growth, induces apoptosis and autophagy in HCT116 and SW480 xenograft models. (A and B) The images of tumors are shown in the left panel and the weights of tumor are plotted in the right panel. (C and D) The results of sodium selenite treatment on the body weight of mice. (E) Histopathological examination of the tumors and liver with H\&E staining in the selenite-treated group and the control group (magnification, $\mathrm{x} 200)$.

hyperchromatic spindle-shaped cells and irregularly dispersed chromatin with a high nuclear/cytoplasmic ratio (Fig. 3E). These results collectively showed that selenite treatment inhibited tumor growth in both the HCT116 and SW480 colon xenograft models.

To further analyze the effect of selenite on apoptosis and autophagy in the xenograft models, we exploited western blotting and immunohistochemical assays to analyze changes in levels of apoptosis and autophagy markers in the tissues. More cleaved PARP and caspase-9 were observed in the selenite-treated samples (Fig. 3G). Autophagy markers,
Beclin-1 and LC3 were increased in the context of selenite treatment. Consistently, p62 was downregulated in the selenite-treated tumors, and these results were consistence with those in the cell culture experiments. Additionally, in the immunohistochemical experiments (Fig. 3F) we also verified the conclusion that selenite treatment induced apoptosis and autophagy in the xenograft tumors.

Reactive oxygen species (ROS) play a pivotal role in selenite-induced apoptosis and autophagy in CRC cells. To explore the effect of ROS on selenite-induced apoptosis 
F

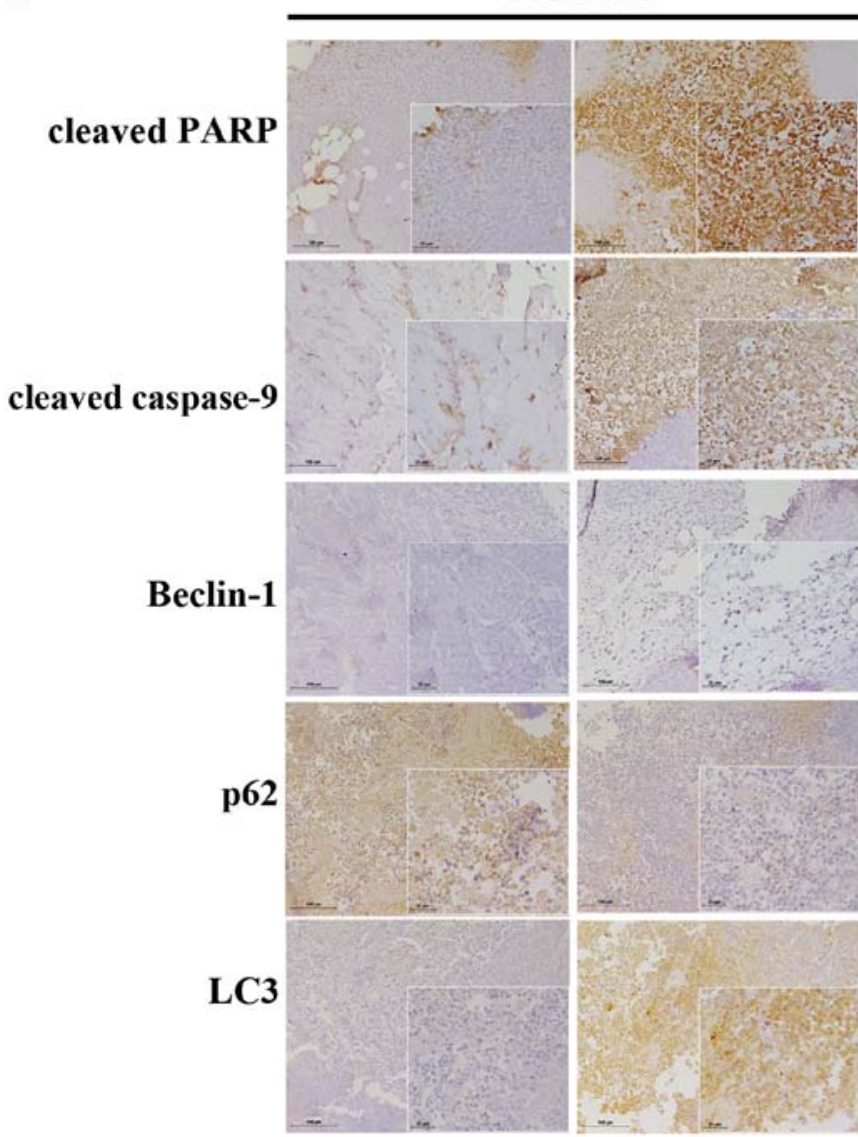

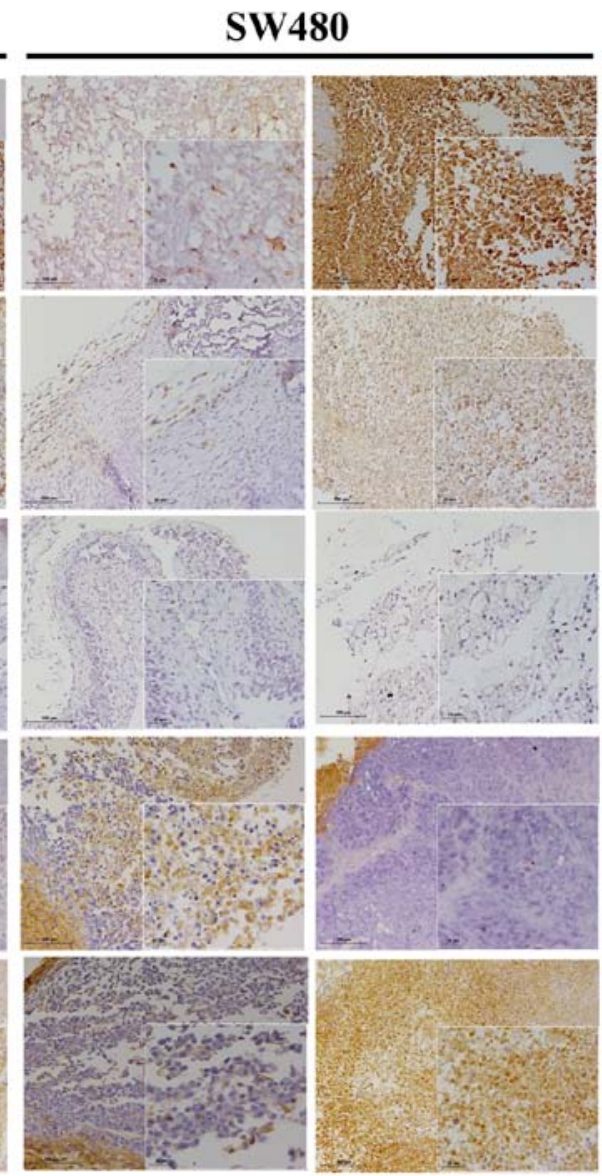

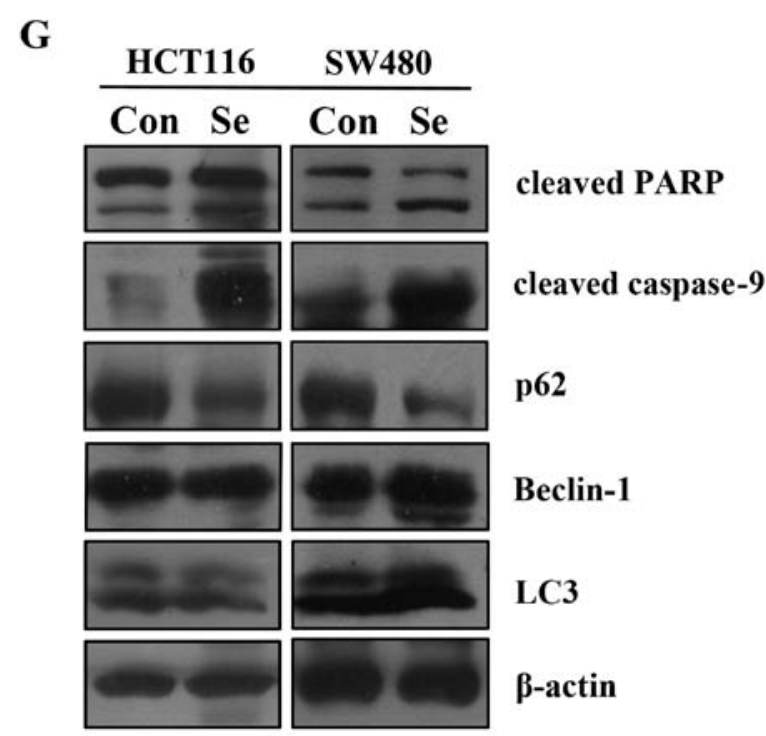

Figure 3. Continued. (F) Selenite-treatement regulates the apoptosis and autophagy proteins in vivo. (G) Western blot analysis of the expression of cleaved PARP, cleaved caspase-9, p62, Beclin-1 and LC3 in the HCT116 and SW480 xenograft tumors.

and autophagy, we modulated the ROS level in cells using MnTMPyP and $\mathrm{H}_{2} \mathrm{O}_{2}$. When ROS in CRC cells were scavenged with MnTMPyP, the punctate of LC3 disappeared (Fig. 4A) and cleaved PARP was decreased significantly even in the presence of selenite treatment (Fig. 4C). While the cells were pretreated with $\mathrm{H}_{2} \mathrm{O}_{2}$ to augment ROS level, we observed increased punctate of LC3 from confocal (Fig. 4A) and increased PARP cleavage from western blot results (Fig. 4C). Accordingly, from Annexin V/PI double staining assay, we found that the apoptotic rate was decreased when MnTMPyP was added. The opposite results were shown when using $\mathrm{H}_{2} \mathrm{O}_{2}$ compared with the MnTMPyP-treated cells (Fig. 4B). Finally, we detected the change in the autophagy marker LC3 in the samples treated with MnTMPyP and found a decrease in the 
A
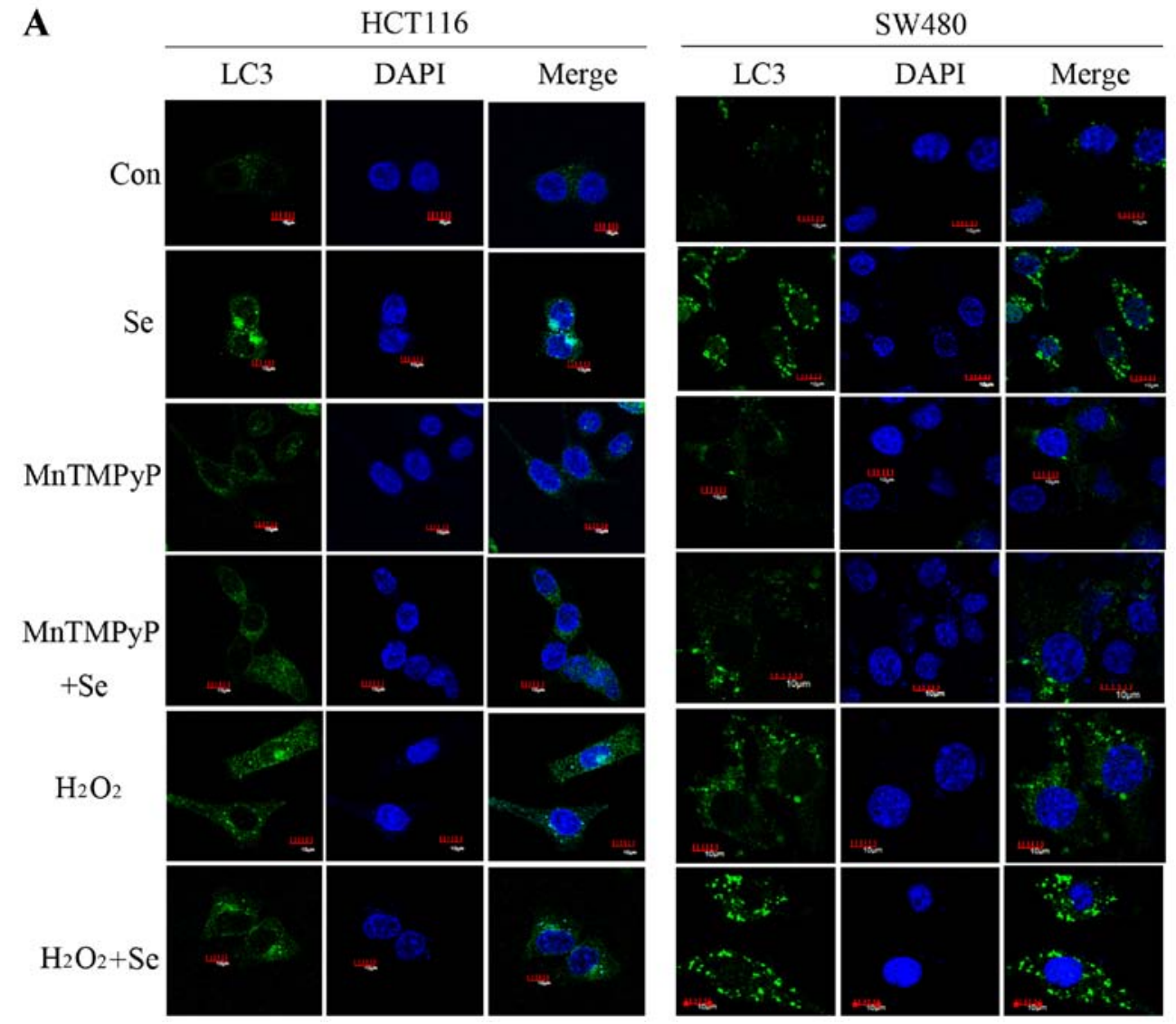
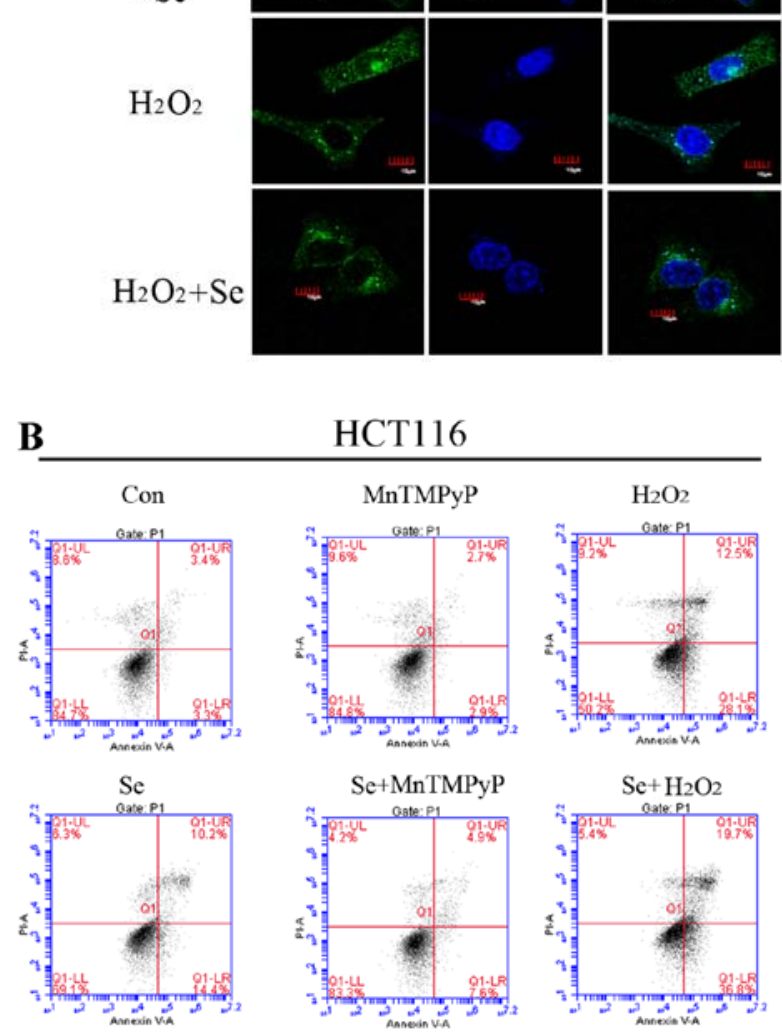

HCT116
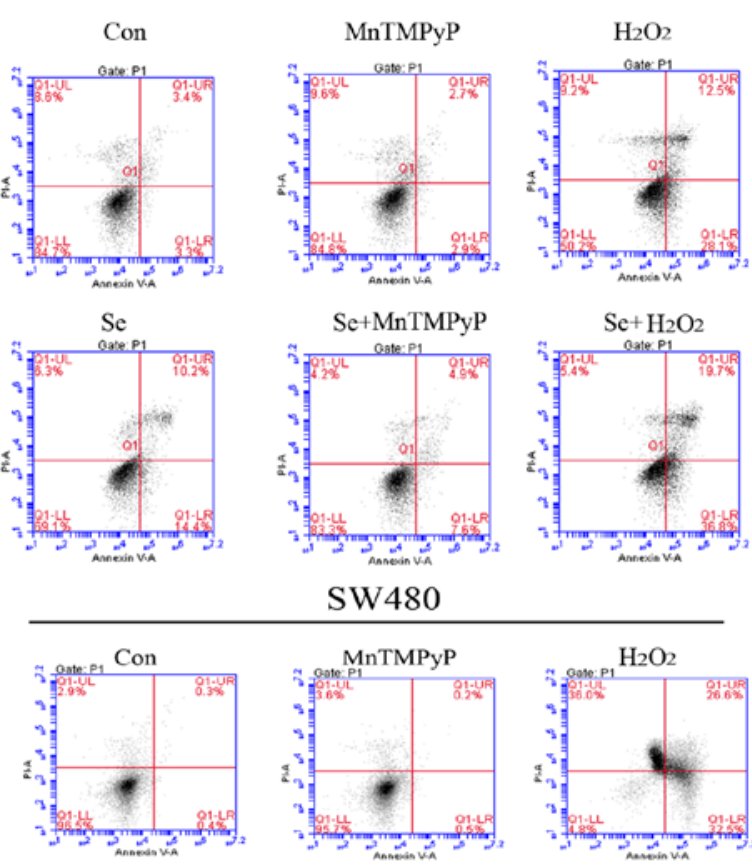

SW480
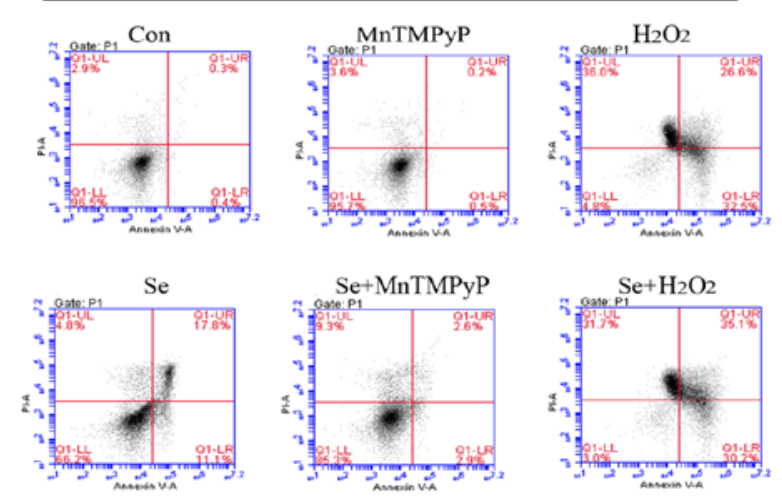
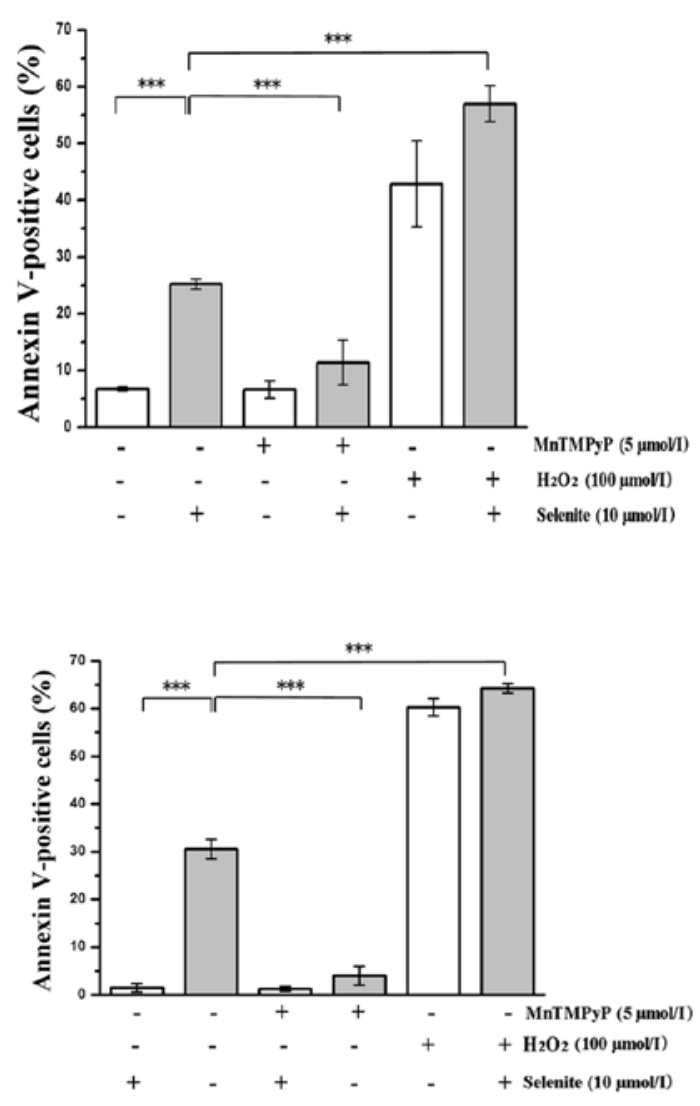

Figure 4. ROS are involved in the regulation of apoptosis and autophagy in HCT116 and SW480 CRC cells. (A) Cell samples were pretreated with MnTMPyP and $\mathrm{H}_{2} \mathrm{O}_{2}$ and then treated with selenite for $24 \mathrm{~h}$. Green signal indicates LC3, and nuclei were stained with DAPI solution. Scale bar, $10 \mu \mathrm{m}$. (B) Flow cytometry results of the samples from selenite-treated HCT116 and SW480 CRC cells for $24 \mathrm{~h}$ with or without MnTMPyP and $\mathrm{H}_{2} \mathrm{O}_{2}$. 

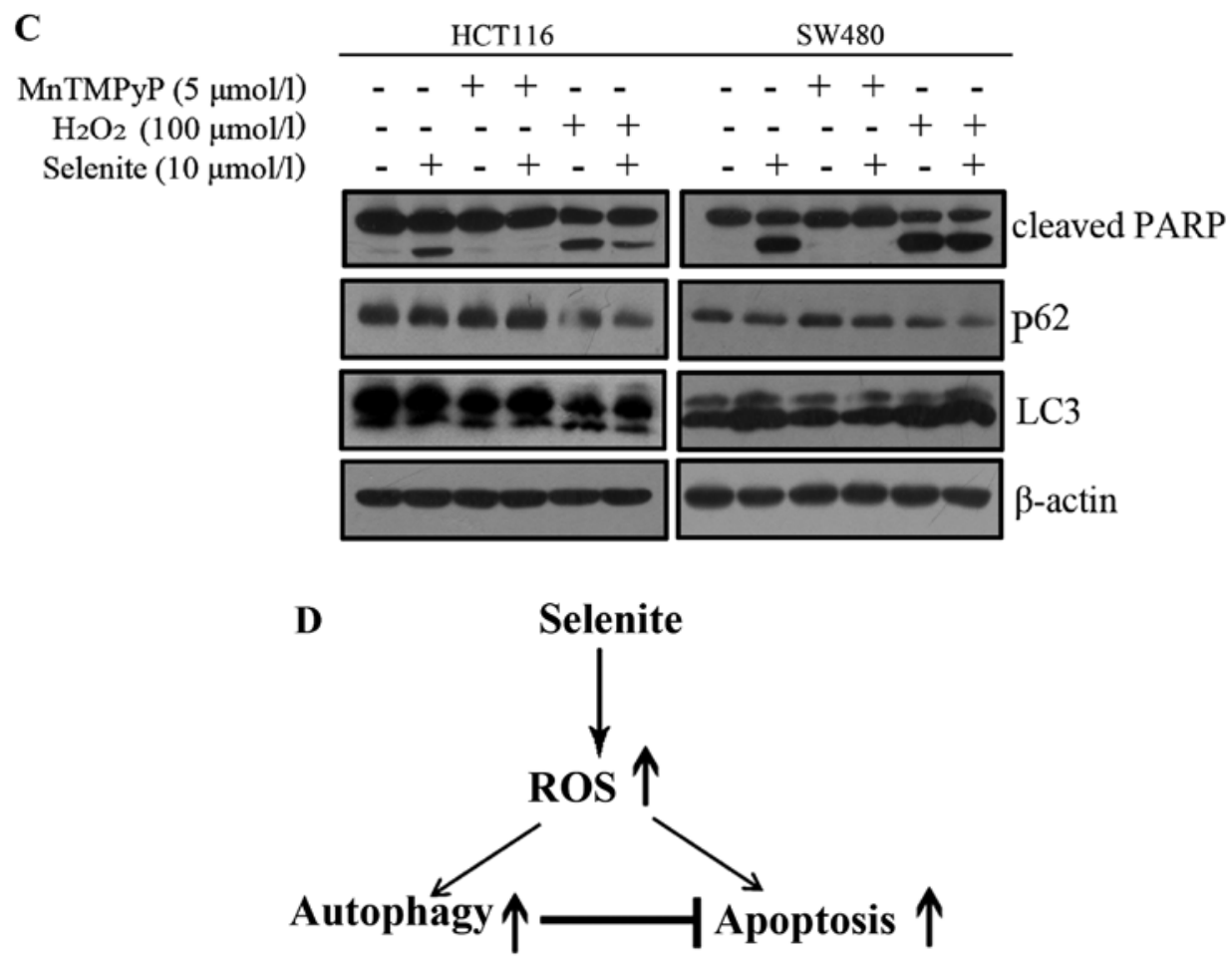

Figure 4. Continued. (C) Western blot analysis of the expression of cleaved PARP and LC3. (D) Schematic illustration of the crosstalk between selenite-induced autophagy and apoptosis in CRC cells.

conversion of LC3. We also observed an opposite trend of change in the $\mathrm{H}_{2} \mathrm{O}_{2}$-treated cells (Fig. 4C). We concluded that selenite-induced apoptosis and autophagy may be caused by ROS through some unknown mechanism.

\section{Discussion}

In the present study, we found that sodium selenite induced apoptosis and autophagy in colorectal cancer (CRC) cells Investigation into the molecular mechanism underlying the crosstalk between apoptosis and autophagy bears great significance, particularly for exploiting novel therapies for treating malignant cancer. The relationship between apoptosis and autophagy is very complicated. Autophagy plays an essential role in maintaining cell survival under stress. In some cases, autophagy acts as a pro-survival factor via antagonizing apoptosis. Excessive autophagy also leads to cell death. In our system, we demonstrated that autophagy was activated by selenite treatment. Suppression of autophagy in CRC cells augmented the apoptotic rate in the cells. In the context of further autophagy activation, the apoptotic rate was increased compared with the selenite treatment (Fig. 4D).

Autophagy has been implicated in a plethora of physiological and pathological processes $(24,25)$. It is commonly thought to be activated in cancer cells to sustain carcinogenesis. However, studies also show that autophagy leads to cell death if it persists $(26,27)$. Our previous study showed that sodium selenite induced apoptotic cell death in CRC cells (21). In the present study, we discovered that autophagy was activated. This prompted us to investigate the role of autophagy in selenite-treated CRC cells. We examined the apoptotic rate of CRC cells when selenite-induced autophagy was inhibited by the inhibitor 3-MA and bafilomycin A1. Accordingly, when autophagy was enhanced, cell death decreased. These results support the conclusion that autophagy was a pro-survival mechanism in the selenite-treated CRC cells. Moreover, we inhibited the selenite-induced apoptosis and discovered that it exerted little effect on autophagy. We concluded that seleniteinduced autophagy was a self-rescue mechanism together with occurrence of apoptosis when cells were treated with selenite.

Reactive oxygen species (ROS) are considered an important anticancer factor of many chemotherapy drugs (28-30). Our previous studies also showed that selenite treatment could increase ROS in cancer cells $(21,31)$. Thus, we examined the role of ROS in the crosstalk between apoptosis and autophagy. On one hand, when ROS were depleted by ROS scavenger, both apoptosis and autophagy were inhibited; on the other hand, in the context of $\mathrm{H}_{2} \mathrm{O}_{2}$ treatment, increased ROS caused more apoptosis and autophagy in CRC cells. It is consistent with other studies that ROS are a pivotal factor in causing cell death. These results further show that ROS have an important role in the crosstalk between autophagy and apoptosis.

Besides the in vitro results, we corroborated our findings in xenograft models. We found that sodium selenite treatment inhibited tumor growth in both models. Immunohistochemical staining of apoptotic and autophagy markers indicated that sodium selenite increased autophagy and apoptosis in tumor tissues. Examination of apoptosis and autophagy related proteins confirmed this conclusion. These results collectively revealed that sodium selenite induced apoptosis and autophagy both in vitro and in vivo.

Although we discovered the phenomenon that sodium selenite induces apoptosis and autophagy in CRC cells, the detailed molecular mechanism underlying the crosstalk 
between apoptosis and autophagy warrants further study. Furthermore, the role of ROS and the signaling pathway modulating this complicated relationship between apoptosis and autophagy in selenite-treated $\mathrm{CRC}$ cells require further elucidation. This research may undoubtedly help to elucidate the anticancer mechanisms of selenium. These results provide a theoretical background for the clinical application of selenium.

\section{Acknowledgements}

The present study was supported by the National Natural Science Foundation of China (nos. 31170788, 31340037 and 31271565), the National Natural Science Foundation for Young Scholars of China (no. 31101018), the State Key Laboratory Special Fund (no. 2060204), and the Natural Science Foundation of Beijing (no. 5082015).

\section{References}

1. Mistry HD, Broughton Pipkin F, Redman CW and Poston L: Selenium in reproductive health. Am J Obstet Gynecol 206: 21-30, 2012.

2. Rayman MP: Selenium and human health. Lancet 379: 1256-1268, 2012.

3. Hamdy SM, Latif AK, Drees EA and Soliman SM: Prevention of rat breast cancer by genistin and selenium. Toxicol Ind Health 28: 746-757, 2012

4. Ou Y, Jiang B, Wang X, Ma W and Guo J: Selenium and colorectal adenomas risk: A meta-analysis. Nutr Cancer 64: 1153-1159, 2012.

5. Hurst R, Hooper L, Norat T, Lau R, Aune D, Greenwood DC, Vieira R, Collings R, Harvey LJ, Sterne JA, et al: Selenium and prostate cancer: Systematic review and meta-analysis. Am J Clin Nutr 96: 111-122, 2012.

6. Lotan Y, Goodman PJ, Youssef RF, Svatek RS, Shariat SF, Tangen CM, Thompson IM Jr and Klein EA: Evaluation of vitamin $\mathrm{E}$ and selenium supplementation for the prevention of bladder cancer in SWOG coordinated SELECT. J Urol 187: 2005-2010, 2012.

7. Klein EA, Thompson IM Jr, Tangen CM, Crowley JJ, Lucia MS, Goodman PJ, Minasian LM, Ford LG, Parnes HL, Gaziano JM, et al: Vitamin $\mathrm{E}$ and the risk of prostate cancer: The Selenium and Vitamin E Cancer Prevention Trial (SELECT). JAMA 306: 1549-1556, 2011.

8. Králová V, Benešová $S$, Cervinka $M$ and Rudolf E: Seleniteinduced apoptosis and autophagy in colon cancer cells. Toxicol In Vitro 26: 258-268, 2012.

9. Guo F, Monsefi N, Moritz A and Beiras-Fernandez A: Selenium and cardiovascular surgery: An overview. Curr Drug Saf 7: $321-327,2012$

10. Jiang $\mathrm{C}, \mathrm{Hu} \mathrm{H}$, Malewicz B, Wang $\mathrm{Z}$ and Lü J: Selenite-induced p53 Ser-15 phosphorylation and caspase-mediated apoptosis in LNCaP human prostate cancer cells. Mol Cancer Ther 3: 877-884, 2004.

11. Sanmartín C, Plano D, Sharma AK and Palop JA: Selenium compounds, apoptosis and other types of cell death: An overview for cancer therapy. Int J Mol Sci 13: 9649-9672, 2012.

12. Kitisin K and Mishra L: Molecular biology of colorectal cancer: New targets. Semin Oncol 33 (Suppl 11): S14-S23, 2006.
13. Maiuri MC, Zalckvar E, Kimchi A and Kroemer G: Self-eating and self-killing: Crosstalk between autophagy and apoptosis. Nat Rev Mol Cell Biol 8: 741-752, 2007.

14. Rubinstein AD and Kimchi A: Life in the balance - a mechanistic view of the crosstalk between autophagy and apoptosis. J Cell Sci 125: 5259-5268, 2012.

15. Booth LA, Tavallai S, Hamed HA, Cruickshanks N and Dent P: The role of cell signalling in the crosstalk between autophagy and apoptosis. Cell Signal 26: 549-555, 2014.

16. Su M, Mei Y and Sinha S: Role of the crosstalk between autophagy and apoptosis in cancer. J Oncol 2013: 102735, 2013.

17. Fimia GM and Piacentini M: Regulation of autophagy in mammals and its interplay with apoptosis. Cell Mol Life Sci 67: 1581-1588, 2010.

18. Luo H, Yang Y, Duan J, Wu P, Jiang Q and Xu C: PTEN-regulated $\mathrm{AKT} / \mathrm{FoxO} 3 \mathrm{a} / \mathrm{Bim}$ signaling contributes to reactive oxygen species-mediated apoptosis in selenite-treated colorectal cancer cells. Cell Death Dis 4: e481, 2013.

19. Ren Y, Huang F, Liu Y, Yang Y, Jiang Q and Xu C: Autophagy inhibition through PI3K/Akt increases apoptosis by sodium selenite in NB4 cells. BMB Rep 42: 599-604, 2009.

20. Li J, Zuo L, Shen T, Xu CM and Zhang ZN: Induction of apoptosis by sodium selenite in human acute promyelocytic leukemia NB4 cells: Involvement of oxidative stress and mitochondria. J Trace Elem Med Biol 17: 19-26, 2003.

21. Luo H, Yang Y, Huang F, Li F, Jiang Q, Shi K and Xu C: Selenite induces apoptosis in colorectal cancer cells via AKT-mediated inhibition of $\beta$-catenin survival axis. Cancer Lett 315: 78-85, 2012.

22. Jiang Q, Wang Y, Li T, Shi K, Li Z, Ma Y, Li F, Luo H, Yang Y and $\mathrm{Xu} C$ : Heat shock protein 90-mediated inactivation of nuclear factor- $\kappa \mathrm{B}$ switches autophagy to apoptosis through becnl transcriptional inhibition in selenite-induced NB4 cells. Mol Biol Cell 22: 1167-1180, 2011.

23. Yamamoto A, Tagawa Y, Yoshimori T, Moriyama Y, Masaki R and Tashiro Y: Bafilomycin A1 prevents maturation of autophagic vacuoles by inhibiting fusion between autophagosomes and lysosomes in rat hepatoma cell line, H-4-II-E cells. Cell Struct Funct 23: 33-42, 1998 .

24. Eskelinen E-L and Saftig P: Autophagy: A lysosomal degradation pathway with a central role in health and disease. Biochim Biophys Acta 1793: 664-673, 2009.

25. Martinet W, Agostinis P, Vanhoecke B, Dewaele M and De Meyer GR: Autophagy in disease: A double-edged sword with therapeutic potential. Clin Sci 116: 697-712, 2009.

26. Buchser WJ, Laskow TC, Pavlik PJ, Lin HM and Lotze MT: Cell-mediated autophagy promotes cancer cell survival. Cancer Res 72: 2970-2979, 2012.

27. Janku F, McConkey DJ, Hong DS and Kurzrock R: Autophagy as a target for anticancer therapy. Nat Rev Clin Oncol 8: 528-539, 2011.

28. Pilarczyk B, Jankowiak D, Tomza-Marciniak A, Pilarczyk R, Sablik P, Drozd R, Tylkowska A and Skólmowska M: Selenium concentration and glutathione peroxidase (GSH-Px) activity in serum of cows at different stages of lactation. Biol Trace Elem Res 147: 91-96, 2012.

29. Tinggi U: Selenium: Its role as antioxidant in human health. Environ Health Prev Med 13: 102-108, 2008.

30. Zou YF, Niu PY, Gong ZY and Yuan J: Role of reactive oxygen species in sodium selenite induced DNA damage in HepG2 cells. Wei Sheng Yan Jiu 35: 291-293, 2006 (In Chinese).

31. Li ZS, Shi KJ, Guan LY, Cao TM, Jiang Q, Yang Y and Xu CM: ROS leads to MnSOD upregulation through ERK2 translocation and p53 activation in selenite-induced apoptosis of NB4 cells. FEBS Lett 584: 2291-2297, 2010. 